\title{
Impact of a simulated practice program in the construction of self-confidence for intervention in emergencies and its association with knowledge and performance
}

José Carlos Amado Martins *1,2, Verónica R. Coutinho ${ }^{1,2}$, Rui C. Baptista ${ }^{1,2}$, Luís M. Oliveira ${ }^{1,2}$, Rui F. Gonçalves ${ }^{1,2}$, Luís A. Paiva ${ }^{1,2}$, Alessandra Mazzo ${ }^{3,4}$, Manuel A. Rodrigues ${ }^{1,2}$, Isabel A.C. Mendes 3,4

${ }^{1}$ Nursing School of Coimbra, Coimbra, Portugal

${ }^{2}$ WHO Collaborating Centre for Nursing Practice and Research, Coimbra, Portugal

${ }^{3}$ College of Nursing, University of São Paulo at Ribeirao Preto, Ribeirao Preto, Brazil

${ }^{4}$ WHO Collaborating Centre for Nursing Research Development, Coimbra, Portugal

Received: May 12, 2016

DOI: $10.5430 /$ jnep.v7n1p45
Accepted: August 15, 2016

Online Published: August 18, 2016

URL: http://dx.doi.org/10.5430/jnep.v7n1p45

\begin{abstract}
The objective was to assess the impact of a simulated practice program on the construction of self-confidence for intervention in emergencies and its association with knowledge and performance. This is a quasi-experimental study without control group, with assessment before and after a 15-hour simulated practice program, in nursing students. The students' self-confidence increased significantly as a result of simulated practice with positive and statistically significant association between practical assessment and self-confidence levels.
\end{abstract}

Key Words: Simulation, Self-confidence, Emergency, Nursing

\section{INTRODUCTION}

A large body of scientific evidence describes the many benefits of using simulation in professional health education, especially high-fidelity simulation. Examples of these benefits include increased student satisfaction; ${ }^{[1-4]}$ learning gains ${ }^{[5,6]}$ increased self-confidence to intervene in different contexts; ${ }^{[7-9]}$ more appropriate use of knowledge and competences; ${ }^{[5,6]}$ transferability of competences to clinical practice ${ }^{[1,10-13]}$ global competency development, such as clinical judgment, priority setting, decision making, accomplishment of correct actions, teamwork and correction of errors without the effects of these errors on the patients. ${ }^{[2]}$

Simulation is a stimulating tool in the learning process, and institutions and trainers increasingly invest in this area.

As regards intervention in emergencies, the nurses' preparation is a core aspect since they are frequently the first to respond to these situations. Their interventions should be of high quality and implemented rapidly. ${ }^{[14]}$ For nurses' response in an emergency situation to be of high-quality, upto-date knowledge ${ }^{[15]}$ and technical, relational and ethical competences $^{[16]}$ are needed, as well as the confidence in the ability to use this knowledge and competences in the best

\footnotetext{
*Correspondence: José Carlos Amado Martins; Email: jmartins@esenfc.pt; Address: Nursing School of Coimbra, R. 5 de outubro, Ap 7001, Portugal.
}

Published by Sciedu Press 
way possible, without errors and with correct decisions. ${ }^{[17]}$

Self-confidence, also described as self-efficacy, is always related to a task or behavior. ${ }^{[18]}$ Confidence is an attitude, frequently related to repeated experiences and accompanied by a realistic perception of individual weaknesses and potentials.

Confidence is an important variable in nursing education. ${ }^{[19]}$ Students with higher levels of self-confidence have a greater probability of successful interventions, as they are able to test and use their competences more easily. ${ }^{[19]}$ Even if they possess appropriate knowledge and skills, nurses are generally reluctant to start certain interventions, unless they feel confident to do so. ${ }^{[17]}$ Individuals with a greater sense of self-efficacy or self-confidence are more willing to accept challenges and recover faster from failure. ${ }^{[19]}$

The development of self-confidence is a key component in correct decision making in clinical contexts and associated judgment processes. ${ }^{[20]}$ Various studies show that self-confidence to respond to emergency situations increases when factors like repeated practice ${ }^{[19]}$ and simulation training are present. ${ }^{[2,9,19,21-25]}$

In a recent systematic review ${ }^{[26]}$ on high-fidelity simulation, although the qualitative studies indicated that self-confidence and competences were variables with positive results, the quantitative studies did not confirm these results. So, the authors suggested further research with larger samples and validated assessment instruments. Hence, in this study, the intent was not only to assess the impact of simulated practice on the construction of self-confidence for intervention in emergencies, but also analyze its association with the knowledge and competences demonstrated.

\section{MATERIAL AND METHODS}

Quasi-experimental study without a control group, ${ }^{[27]}$ in which assessments took place at two moments: before and after a 15-hour simulated practice program. The simulated practice took place at the simulation center of a public nursing school in Portugal and was preceded by a theoretical component, in which the knowledge about nursing interventions in adult and pediatric emergency situations was presented, discussed and assessed, in accordance with the 2010 recommendations of the European Resuscitation Council. ${ }^{[15]}$

The simulated practice program consisted of a 3-hour session per week during five weeks. The first two weeks were dedicated to learning specific techniques (basic airway, advanced airway and monitoring and manual defibrillation), becoming familiar with the material and equipment, and team training in adult and pediatric basic life support. The next three weeks were used for the resolution of scenarios (cardiac arrest in adults and children, hypovolemic shock, severe hypoglycemia, acute pulmonary edema, angina with cardiac arrest, anaphylactic reaction to medication, and convulsions due to intracranial hypertension).

To solve the scenarios, the students had realistic material and equipment at their disposal. Medium- (adult and ju-

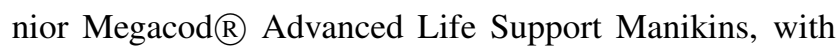
VitalSim $\cap$, by Laerdal $\cap)$ ) and high-fidelity (iStan $\cap$ and PediaSim $(\mathrm{R}$ by Meti $\mathrm{R})$ patient simulators were used.

The scenarios were constructed and a group of experts determined their face and content validity before the practices. The training and evaluation scenarios were developed by the teachers of the Emergency Nursing curricular unit, who have a vast experience in this field. To ensure the accuracy in the process, an instructor's manual was used. The previous teachers' training ensures reliability in developing scenarios and interrater reliability in the evaluation process, with a percentage of agreement above 95\% (Cohen's kappa). ${ }^{[27]}$

All students had the opportunity to participate in different scenarios and use the same material and equipment. The scenarios were developed in groups of four students. After solving each scenario, a non-judgmental ${ }^{[28,29]}$ debriefing session was held, centered on reflections about practice in the attempt to consolidate knowledge. In the simulation classes, we used the conceptual model proposed by Jeffries, ${ }^{[30]}$ that includes the teacher, the student, the educational practices and the simulation design as agents influencing the results.

\subsection{Population and sample}

All students (320 students) enrolled in the curricular unit of Emergency Nursing (4th year of teaching diploma program in Nursing) were invited to participate in the study. A total of 285 students accepted to participate. From this group, 162 were randomly selected. Participation in all activities was set as the inclusion criterion.

\subsection{Instruments}

The following data sources were used: questionnaire with demographic questions; the Self-Confidence Scale (pv); the results of the knowledge test; and the results of the practical assessment.

The Self-Confidence Scale (portuguese version) (pv ${ }^{[31]}$ is a 12-item scale divided into three dimensions: breathing, circulation and neurological. Each dimension includes four items assessing the self-confidence to intervene in an emergency situation. Cronbach's alpha reveals the high reliability of the scale: 0.917 in before assessment and 0.919 after assessment. These values are identical to the coefficients obtained in the 
scale validation process for the Portuguese language.

Knowledge was assessed through a multiple-choice test, including 40 questions with five alternative responses. The test included questions on the nurses' response to critically ill patients, highlighting basic and advanced life support. It was developed by the teachers of the curricular unit and previously implemented and solved by four teachers, ensuring validity and reliability. This assessment was done at the end of the theoretical component through simulated practice. For student approval, the minimum grade required was 10 points and the maximum was 20 points.

For the practical assessment, a structured observation grid was used at the end of the simulated practice. The grid is commonly used in the practical assessment of emergency and reanimation training. ${ }^{[32]}$ It includes items related to the identification of the situation, assessment and intervention in the airway, breathing, circulation and neurological areas, collection of patient history, and active search for causes of cardiorespiratory arrest. The students' performance was classified as follows: "well done, in the right moment"; "done with short delay or small inaccuracies"; "done with errors or delay"; and "not done or done".

Two teachers assessed the students so as to ensure accuracy. Disagreements were solved by group discussion involving all teachers of the curricular unit. The scenario being assessed involved a situation of cardiorespiratory arrest with defibrillable rhythm, caused by hypovolemia due to abdominal hemorrhage in a surgical patient. For student approval, the minimum grade required was 10 and the maximum was 20 . The results of the theoretical and practical assessment were grouped, using quartiles.

\subsection{Formal and ethical procedures}

The research obtained a favorable opinion from the Ethics Committee (P1-09/2010) and was authorized by the School President.

All ethical principles of research involving human beings were met. ${ }^{[33]}$ Students were informed about the research objectives and the voluntary nature of their participation. Students were ensured that their participation in the study would not influence their assessment in the curricular unit.
An informed consent form was used.

\subsection{Statistical analysis}

Data were analyzed using the IBM-SPSS (Statistical Package for the Social Sciences) software, version 22. The Lilliefors corrected Kolmogorov-Smirnov test was applied, which revealed that the distribution of the self-confidence rates was non-normal, both in the pre- and in the post-assessment. Thus, non-parametric tests were used. ${ }^{[34]}$ For all tests, significance was set at $p<.05$.

\section{Results}

More than three quarters $(84.6 \%)$ of the participants were women. The mean age was 22.02 years and the median was 22 years, with a mode of 21 years, ranging between 21 and 40 years. The standard deviation was 2.28 years. With a possible variation between 1 and 5 , the scores on the self-confidence scale in the pre-assessment were below the midpoint ( 3 points), except for the breathing dimension, with a score of 3.08 points. The global scale score ranged between 2.00 and 4.17 points. In the post-assessment, the scores increased by more than $10.0 \%$ in all dimensions and in the global scale, with less dispersed scores. As for the global scale, the mean score varied between 2.33 and 4.83 points. In both assessments, the breathing dimension obtained the highest scores, while the opposite was true for the neurological dimension. The Wilcoxon test for paired samples showed that these differences in students' self-confidence scores are highly significant in statistical terms $(p<.001)$ (see Table 1$)$.

The search for possible associations between the students' theoretical and practical assessments and their selfconfidence levels, using the Kruskal-Wallis test, showed that there were no significant associations between theoretical assessment and self-confidence, both in the pre- and in the post-assessment. Nevertheless, significant associations were found between practical assessment and self-confidence scores in the post-assessment. Testing pairwise using the Mann-Whitney U test, associations between all pairs were found, except between group 15-16 points and group 16-17 points. Higher grades in practical assessment were associated with higher self-confidence scores. Table 2 shows the post-assessment results.

Table 1. Self-confidence of students to intervene in emergencies before and after simulated practice and Wilcoxon tests

\begin{tabular}{|c|c|c|c|c|c|c|}
\hline \multirow{2}{*}{ Self-confidence } & \multicolumn{2}{|c|}{ Pre-assessment } & \multicolumn{2}{|c|}{ Post-assessment } & \multicolumn{2}{|c|}{ Wilcoxon test } \\
\hline & Mean & Standard Deviation & Mean & Standard Deviation & 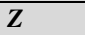 & $p$ \\
\hline Neurologic dimension & 2.76 & 0.55 & 3.39 & 0.50 & -9.17 & .000 \\
\hline Respiratory dimension & 3.10 & 0.50 & 3.68 & 0.49 & -9.19 & .000 \\
\hline Cardiac dimension & 2.72 & 0.51 & 3.45 & 0.51 & -10.21 & .000 \\
\hline Global self-confidence & 2.86 & 0.46 & 3.51 & 0.44 & -10.13 & .000 \\
\hline
\end{tabular}


Table 2. Kruskal-Wallis test between self-confidence scores in post-assessment and theoretical and practical assessment results

\begin{tabular}{|c|c|c|c|c|c|}
\hline $\begin{array}{l}\text { Self-confidence } \\
\text { (post-assessment) }\end{array}$ & $\begin{array}{l}\text { Points in } \\
\text { evaluation }\end{array}$ & $\begin{array}{l}\text { Mean Rank in } \\
\text { Knowledge assessment }\end{array}$ & $\begin{array}{l}\text { Kruskal-Wallis } \\
\text { test }\end{array}$ & $\begin{array}{l}\text { Mean Rank in } \\
\text { Practical assessment }\end{array}$ & $\begin{array}{l}\text { Kruskal-Wallis } \\
\text { test }\end{array}$ \\
\hline \multirow{4}{*}{ Neurologic dimension } & $<15$ & 142.78 & & 119.63 & \multirow{4}{*}{$\begin{array}{l}\chi^{2}=14.04 \\
p=.003\end{array}$} \\
\hline & $15-16$ & 139.73 & $\chi^{2}=0.40$ & 149.68 & \\
\hline & $16-17$ & 126.07 & $p=.941$ & 137.83 & \\
\hline & $>17$ & 119.50 & & 173.23 & \\
\hline \multirow{4}{*}{ Respiratory dimension } & $<15$ & 142.47 & & 106.49 & \multirow{4}{*}{$\begin{array}{l}\chi^{2}=24.26 \\
p=.000\end{array}$} \\
\hline & $15-16$ & 135.08 & $\chi^{2}=1.47$ & 150.90 & \\
\hline & $16-17$ & 160.64 & $p=.690$ & 151.45 & \\
\hline & $>17$ & 67.50 & & 171.47 & \\
\hline \multirow{4}{*}{ Cardiac dimension } & $<15$ & 141.41 & & 113.18 & \multirow{4}{*}{$\begin{array}{l}\chi^{2}=19.59 \\
p=.000\end{array}$} \\
\hline & $15-16$ & 136.85 & $\chi^{2}=0.258$ & 141.00 & \\
\hline & $16-17$ & 146.36 & $p=.968$ & 147.23 & \\
\hline & $>17$ & 110.00 & & 176.67 & \\
\hline \multirow{4}{*}{ Global self-confidence } & $<15$ & 140.54 & & 108.70 & \multirow{4}{*}{$\begin{array}{l}\chi^{2}=22.22 \\
p=.000\end{array}$} \\
\hline & $15-16$ & 132.06 & $\chi^{2}=0.782$ & 144.92 & \\
\hline & $16-17$ & 138.00 & $p=.854$ & 142.72 & \\
\hline & $>17$ & 81.50 & & 177.30 & \\
\hline
\end{tabular}

\section{Discussion}

In this study, the results demonstrate that, in general, students' self-confidence to intervene in an emergency situation corresponded to 2.85 points in the assessment before the simulated practice (below the midpoint of the scale) and increased to 3.50 points after these practices. At the same time, the minimum and maximum scores increased and the dispersion was reduced. The Wilcoxon tests show that the increase in the mean scores for the global scale and the dimensions is statistically highly significant $(p<.001)$, which reveals a positive impact of the simulated practice on the construction of the students' self-confidence to intervene in emergency situations. Other studies ${ }^{[35,36]}$ have shown the effectiveness of simulation as a strategy to enhance nurses' self-confidence in triage at the emergency service, with positive influence on the ability to make correct decisions.

Simulation has proven to be an excellent strategy for competency building in nursing students, ${ }^{[2,19,28,37]}$ as well as for improving nurses' self-confidence $\mathrm{e}^{[7-9,14,37-40]}$ to respond to emergency situations, which was also evident in this study. The possibility of training in safe simulated environments and being able to make errors without direct risks to the patients promoted students' learning. The same was true for debriefing, a strategy that helps participants to explore, analyze and synthesize their thinking processes, emotional status and other aspects that might improve their performance in real-life situations. ${ }^{[25]}$

In both assessment moments, students scored higher in the breathing dimension and lower in the neurological dimen- sion. The greater simplicity of nursing assessments and interventions in the breathing area explain the higher scores. On the other hand, the greater complexity in the identification and interpretation of neurological signs and symptoms and the more difficult interventions make students feel less confident about assessing and intervening appropriately in this dimension. An additional factor to help explain this is the greater internalization and structuring of thought in the breathing area, as interventions in any emergency scenario start with the approach of the airway and breathing (A and B). Again, repeated practice seems to positively influence self-confidence, as mentioned by other authors. ${ }^{[2,19]}$ This deliberate practice helps to develop structured thinking and consolidate the sequence of actions, especially patient assessment.

Kruskal-Wallis tests revealed no statistically significant association between the dimensions and the global selfconfidence scale and the knowledge assessment scores.

Some studies ${ }^{[40,41]}$ have shown the contribution of simulation to increase knowledge, but they usualy use students' self-assessment. In a systematic review, Laschinger et al. ${ }^{[35]}$ found no conclusive results in this area.

Knowledge can provide a false sense of confidence and the confrontation with practice helps to build this confidence more realistically. If knowledge assessment was repeated after the simulated practice, the results might be different, as various authors have reported the contribution of simulation to the consolidation of previously acquired knowledge and 
its link with practice, and even to the acquisition of new knowledge. ${ }^{[5,6,37]}$ Statistically significant associations were found between the students' self-confidence levels and the practical assessment, in the post-assessment.

Some authors have suggested that self-confidence is associated with competence, ${ }^{[2,7-9,19,30]}$ although with some reservations.

Despite this, several studies have demonstrated the strengthening of self-confidence and clinical competences. Examples include the response to obstetric emergencies, ${ }^{[43]}$ the response to emergencies by nursing and medical students, ${ }^{[1,42]}$ resuscitation in pediatrics by physicians and nurses, ${ }^{[40]}$ or advanced cardiac life support by physicians, nurses and paramedics. ${ }^{[41,44]}$

The contribution of simulation to help students make an appropriate use of the knowledge and competences ${ }^{[5,6,42]}$ is something that can help to explain this link between students' self-confidence and practical assessment.

\section{Conclusions}

Simulated practice is a good teaching/learning strategy, which contributes to significantly increase the students' lev- els of self-confidence.

In the group under analysis, self-confidence was positively associated with the score obtained in the practical assessment, that is, more confident students were more likely to perform better. Self-confidence is an important variable for action in emergency situations, whether related to a prompt response, the quality of the actions or even the occurrence of errors. With regard to the association between self-confidence and knowledge, although knowledge was assessed before the simulated practice, this correlation was not significant in the study sample. Simulation is an important tool to prepare nurses to respond to emergency situations, which justifies the investment of nursing schools and faculty members. The specific characteristics of the student group under analysis and the method used in this study are limiting factors for the generalization of the results. Future studies will contribute to enhance knowledge in the area.

\section{ACKNOWLEDGEMENTS}

To the Foundation for Science and Technology (Portugal) for the Post-Doctoral Scholarship of the first author.

\section{CONFlicts of InTEREST Disclosure}

The authors declare that there is no conflict of interest.

\section{REFERENCES}

[1] Reilly A, Spratt C. The perceptions of undergraduate student nurses of high-fidelity simulation-based learning: A case report from the University of Tasmania. Nurse Education Today. 2007; 27(6): 542550. PMid:17069935 http://dx.doi.org/10.1016/j.nedt . 20 06.08 .015

[2] Martins J, Mazzo A, Baptista R, et al. The simulated clinical experience in nursing education: a historical review. Acta Paulista de Enfermagem. 2012; 25(4): 619-625. http://dx.doi.org/10.15 90/S0103-21002012000400022

[3] Baptista R, Pereira M, Martins J. Perception of Nursing students on high-fidelity practices: a phenomenological study. Journal of Nursing Education and Practice. 2016; 6(8): 10-21. http://dx .doi .org/1 $0.5430 /$ jnep.v6n8p10

[4] Baptista R, Martins J, Pereira M, et al. High fidelity simulation on the nursing degree: gains perceived by students. Revista de Enfermagem Referência. 2014; IV(1): 131-140.

[5] Butler K, Veltre D, Brady D. Implementation of Active Learning Pedagogy Comparing Low-Fidelity Simulation Versus High-Fidelity Simulation in Pediatric Nursing Education. Clinical Simulation in Nursing. 2009; 5(4): 129-136. http://dx.doi.org/10.1016/j .ecns.2009.03.118

[6] Swenty C, Eggleston B. The Evaluation of Simulation in a Baccalaureate Nursing Program. Clinical Simulation in Nursing. 2010; 7(5): e181-e187. http://dx.doi.org/10.1016/j.ecns. 2010 .02 .006

Published by Sciedu Press
[7] Smith S, Roehrs C. High-fidelity simulation: factors correlated with nursing student satisfaction and self-confidence. Nursing Education Perspectives. 2010; 30(2): 74-78.

[8] Sinclair B, Fergunson K. Integrating simulated teaching/learning strategies in undergraduate nursing education. International Journal of Nursing Education Scholarship. 2009; 6: 1-11. PMid:19341357 http://dx.doi.org/10.2202/1548-923X. 1676

[9] Blum C, Borglund S, Parcells D. High-fidelity nursing simulation: impact on student self-confidence and clinical competence. International Journal of Nursing Education Scholarship. 2010. PMid:20597857 http://dx.doi.org/10.2202/1548-923X. 2035

[10] Baxter P, Akhtar-Danesh N, Valaitis R, et al. Simulated experiences: Nursing students share their perspectives. Nurse Education Today. 2009; 29(8): 859-866. PMid:19500886 http://dx.doi.org/10. $1016 / j$.nedt. 2009.05.003

[11] Lasater K. The Impact of High-Fidelity Simulation on the Development of Clinical Judgment in Nursing Students: an exploratory study [doctoral thesis]. Portland, Portland State University; 2005.

[12] Kuznar K. Associate degree nursing students' perceptions of learning using a high-fidelity human patient simulator. Teaching and Learning in Nursing. 2007; 2(2): 46-52. http://dx.doi.org/10.1016/j .teln.2007.01.009

[13] McGagie W, Draycott T, Dunn W, et al. Evaluating the impact of simulation on translational patient outcomes. Simulation in Healthcare. 2011; 6: S42-47. PMid:21705966 http://dx.doi .org/10. 1097/SIH. Ob013e318222fde9

[14] Roh Y, Lee W, Chung H, et al. The effects of simulation-based resuscitation training on nurses' self-efficacy and satisfaction. Nurse 
Education Today. 2013; 33(2): 123-128. PMid:22153054 http: //dx.doi.org/10.1016/j.nedt.2011.11.008

[15] Nolan J, Soar J, Zideman D, et al. European Resuscitation Council guidelines for resuscitation 2010. Resuscitation. 2010; 81(1): 12191276. PMid:20956052 http://dx.doi.org/10.1016/j.resus citation.2010.08.021

[16] Martins J. Atuação do enfermeiro no setor de urgências: gestão para o desenvolvimento de competências. In: Malagutti, W, Caetano K. Gestão do serviço de enfermagem no mundo globalizado. Rio de Janeiro: Rubio; 2009.

[17] Maibach E, Schieber R, Carroll M. Self-efficacy in pediatric resuscitation: Implications for education and performance. Pediatrics. 1996; 97(1): 94-99. PMid:8545233

[18] Bandura A. Self-efficacy determinants of anticipated fears and calamities. Journal of Personality and Social Psychology. 1983; 45(2): 464469. http://dx.doi.org/10.1037/0022-3514.45.2.464

[19] Hicks F, Coke L, Li S. Report of findings from the effect of highfidelity simulation on Nursing students' knowledge and performance: a pilot study. Research Brief. 2009; 40.

[20] Buckley T, Gordon C. The effectiveness on high fidelity simulation on medical-surgical registered nurses' ability to recognize and respond to clinical emergencies. Nurse Education Today. 2011; 31(7): 716-721. PMid:20573428 http://dx.doi.org/10.1016/j.ned t. 2010.04 .004

[21] Gordon C, Buckley T. The effect of high-fidelity simulation training on medical-surgical graduate nurses' perceived ability to respond to patient clinical emergencies. The Journal of Continuing Education in Nursing. 2009; 40(11): 491-498. PMid:19904861 http://dx.doi.org/10.3928/00220124-20091023-06

[22] Bambini D, Washburn J, Perkins R. Outcomes of clinical simulation for novice nursing students: communication, confidence, clinical judgment. Nursing Education Research. 2009; 30(2): 79-82.

[23] Buykx P, Kinsman L, Cooper S, et al. FIRST2ACT: Educating nurses to identify patient deterioration - a theory-based model for best practice simulation education. Nurse Education Today. 2011; 31(7): 687-693. PMid:21481992 http://dx.doi.org/10.1016/j.ned t. 2011.03 .006

[24] Griswold S, Ponnuru S, Nishisaki A, et al. The emerging role of simulation education to achieve patient safety: translating deliberate practice and debriefing to save lives. Pediatric Clinics of North America. 2012; 59(6): 1329-1340. PMid:23116529 http: //dx.doi.org/10.1016/j.pcl.2012.09.004

[25] Hope A, Garside J, Prescott S. Rethinking theory and practice: preregistration student nurses experiences of simulation in teaching and learning in the acquisition of clinical skills in preparation for practice. Nurse Education Today. 2011; 31(7): 711-715. PMid:21237536 http://dx.doi.org/10.1016/j.nedt.2010.12.011

[26] Yuan H, Williams B, Fang J. The contribution of high-fidelity simulation to nursing students' confidence and competence: a systematic review. International Nursing Review. 2011; 59(1): 26-33 http://dx.doi.org/10.1111/j.1466-7657.2011.00964.x

[27] Fortin M. Fundamentos e Etapas do Processo de Investigação. Loures: Lusodidacta; 2009.

[28] Coutinho V. Structured debriefing in nursing simulation: students' perceptions. Journal of Nursing Education and Practice. 2016; 6(9): 127-134. http://dx.doi.org/10.5430/jnep.v6n9p127

[29] Kolb M, Grande B, Spahn D. Briefing and debriefing during simulation-based training and beyond: Content, structure, attitude and setting. Best Practice \& Research Clinical Anaesthesiology. 2015;
29(1): 87-96. PMid:25902470 http://dx.doi.org/10.1016/j .bpa.2015.01.002

[30] Jeffries P. Simulation in nursing education from conceptualization to evaluation. New York: National League for Nursing; 2007.

[31] Martins J, Baptista R, Coutinho V, et al. Self-confidence for emergency intervention: adaptation and cultural validation of the Selfconfidence Scale in Nursing students. Revista Latino-Americana de Enfermagem. 2014; 22(4): 554-561. http://dx.doi.org/10.15 90/0104-1169.3128.2451

[32] Ruzafa-Martínez M, López-Iborra L, Martins J. Elaboración de un test para evaluar competencias prácticas de estudiantes de enfermería en reanimación cardiopulmonar avanzada. Congreso Internacional de Innovación Docente. Cartagena: Universidad Politécnica de Cartagena, 2011.

[33] Martins J. Investigação em enfermagem: alguns apontamentos sobre a dimensão ética. Pensar Enfermagem. 2008; 12: 62-66.

[34] Marôco J. Análise estatística com utilização do SPSS. $2^{\mathrm{a}}$ Ed. Lisboa: Edições Sílabo; 2003.

[35] Wolf L, Mass A. The use of human patient simulation in ED triage training can improve nursing confidence and patient outcomes. Journal of Emergency Nursing. 2008; 34(2): 169-171. PMid:18358363 http://dx.doi.org/10.1016/j.jen.2007.11.005

[36] Smith A, Lollar J, Mendenhall J, et al. Use of multiple pedagogies to promote confidence in triage decision making: a pilot study. Journal of Emergency Nursing. 2013; 39(6): 660-666. PMid:22421315 http://dx.doi.org/10.1016/j.jen.2011.12.007

[37] Hur H, Choi H, Jung J, et al. Influence of simulation-based practice on emergency care for patients with dyspnea on learning outcomes in nursing students. Journal of Korean Critical Care Nursing. 2012; 5(1): 12-22.

[38] Jeffries P, Rizzolo M. Designing and Implementing Models for the Innovative Use of Simulation to Teach Nursing Care of Il adults and Children: A national, multi-site, multi-method study. New York: National League for Nursing; 2006.

[39] Arnold J, Johnson L, Tucker S, et al. Comparison of three simulationbased teaching methodologies for emergency response. Clinical Simulation in Nursing. 2013; 9(3): e85-e93. http://dx.doi .org/10. 1016/j.ecns. 2011.09.004

[40] O'Leary F. Paediatric resuscitation training: is e-learning the answer? A before and after pilot study. Journal of Paediatrics and Child Healthcare. 2012; 48(6): 529-533. PMid:22107149 http: //dx.doi.org/10.1111/j.1440-1754.2011.02250.x

[41] Tofil N, Morris J, Peterson D, et al. Interprofessional simulation training improves knowledge and teamwork in nursing and medical students during internal medicine clerkship. Journal of Hospital Medicine. 2014; 9(3): 189-192. PMid:24420579 http://dx.doi . org $/ 10.1002 / \mathrm{jhm} .2126$

[42] Laschinger S, Medves J, Pulling C, et al. Effectiveness of simulation on health profession students' knowledge, skills, confidence and satisfaction. International Journal of Evidence Based Healthcare. 2008; 6(3): 278-302. http://dx.doi.org/10.1111/j.1744-1 $609.2008 .00108 . \mathrm{x}$

[43] Manod C, Voekt C, Gisin M, et al. Optimization of competency in obstetrical emergencies: a role for simulation training. Archives of Gynecology and Obstetrics. 2014; 289(4): 733-738. PMid:24346119 http://dx.doi.org/10.1007/s00404-013-3111-6

[44] Hoadley T. Learning advanced cardiac life support: a comparison study of the effects of low- and high-fidelity simulation. Nursing Education Perspectives. 2009; 30(2): 91-95. PMid:19476072 